\title{
Projected future changes in Marine Cold-Air Outbreaks associated with Polar Lows in the Northern North-Atlantic Ocean
}

\author{
Oskar A. Landgren ${ }^{1} \cdot$ Ivar A. Seierstad ${ }^{1} \cdot$ Trond Iversen $^{1}$
}

Received: 4 October 2018 / Accepted: 20 January 2019 / Published online: 7 February 2019

(c) The Author(s) 2019

\begin{abstract}
Marine Cold-Air Outbreaks (MCAO) can be used as a large-scale measure of the potential for development of Polar Lows in the Northern North Atlantic Ocean during NH winter. We applied an MCAO index to 30 members of the Community Earth System Model Large Ensemble to investigate model-projected future changes in the Nordic and Barents Seas in response to anthropogenic climate change. In agreement with previous studies we found an overall decrease in the MCAO index due to increased tropospheric static stability. We also found a changed seasonal profile, with a stronger decrease in December-January than in February-March, effectively leading to the peak occurring in February rather than January in the Nordic Seas. In the Barents Sea, the reductions were only statistically significant in the autumn and spring, with the winter reduction due to increased static stability was partly balanced by a retracting sea-ice edge. The contribution from circulation changes in mean sea-level pressure was assessed by a cluster analysis in lower-dimensional phase-space, spanned by the projections onto the four leading Empirical Orthogonal Functions. While there was a small but statistically significant increase of the Atlantic Ridge-like pattern, the overall changes in MCAO were dominated by changes in temperature at the sea surface and aloft.
\end{abstract}

Keywords Cold-Air Outbreak · GIN Seas $\cdot$ Barents Sea $\cdot$ Future climate variability $\cdot$ Large ensemble

\section{Introduction}

When a cold air mass, typically originating from an icecovered sea area, is advected over open water, a large flux of latent heat is triggered from the ocean to the atmosphere, due to the (relatively) much higher temperature of the water. This pattern is called a Marine Cold-Air Outbreak (MCAO, Kolstad and Bracegirdle 2008; Mansfield 1974), and is important for the formation of small-scale, marine cyclones, polar lows (PL), which cause severe weather conditions that combine strong winds with heavy snow-fall and freezing sea-spray at the high latitudes.

Due to their small size (diameter $\sim 200$ to $1000 \mathrm{~km}$ ) and short lifetime (1-2 days), polar lows (e.g. Harrold and

Electronic supplementary material The online version of this article (https://doi.org/10.1007/s00382-019-04642-2) contains supplementary material, which is available to authorized users.

Oskar A. Landgren

oskaral@met.no

1 Norwegian Meteorological Institute, Henrik Mohns plass 1, 0313 Oslo, Norway
Browning 1969; Reed 1979; Wilhelmsen 1985; Businger 1985; Emanuel and Rotunno 1989; Nordeng and Rasmussen 1992; Kristjánsson et al. 2011; Rasmussen 2011) have historically been difficult to detect and forecast. They still cannot be well resolved in global climate models, which typically still employ grid mesh widths of $1^{\circ}-2^{\circ}$, thus typically resolving structures with wavelengths larger than a thousand kilometers. MCAO, however, are large-scale phenomena, and can serve as a proxy for conditions governing polar low development.

Kolstad and Bracegirdle (2008) from now KB08, developed an MCAO index, quantifying the lower tropospheric static stability based on potential temperature at $700 \mathrm{hPa}$, sea-surface skin temperature, and surface pressure. They applied it to 13 models from the Coupled Model Intercomparison Project phase 3 (CMIP3) ensemble, and found a future northward shift and weakening of the MCAO. Zahn and von Storch (2010) performed dynamical downscaling with $\sim 50 \mathrm{~km}$ grid mesh width and found a future northward shift of the polar low genesis regions.

Stoll et al. (2018) compared over 20 different criteria for polar low detection using the STARS polar low database (Noer et al. 2011), and reanalysis data from ERA-Interim 
and the Arctic Systems Reanalysis (ASR). They found the MCAO criterium from $K B 08$ to be very close to their most effective criterium.

Romero and Emanuel (2017) used a statistical-deterministic model to investigate PLs in the CMIP5 ensemble. They found an overall reduction in frequency of occurrence, but an increase in the Norwegian and Barents Seas. They analysed the change to be mostly driven by changes in SST and the frequency and intensity of Cold-Air Outbreaks.

Kolstad et al. (2009) from now KBSO9, analysed the same index as $K B 08$ in relation to governing circulation patterns for three different North Atlantic areas, and found a negative correlation $(r=-0.42)$ between North Atlantic Oscillation (NAO) and MCAO indices in the Barents Sea region.

In general, the spread in future climate estimates can be traced to three causes (Hawkins and Sutton 2009): future scenario uncertainty, model process uncertainty, and internal natural variability. The first point relates to the assumed scenarios of socioeconomic pathways, including geopolitical issues and technological advancements. The second point relates to how different modelling groups choose and formulate physical processes in their models, such as subgrid-scale turbulence, deep convection, aerosols and cloud microphysics, radiation, ground-surface processes, or biogeochemistry. The protocol of the CMIP experiments helps to dispense with this issue by using common future scenarios and a standard output format that facilitates sharing and comparing model results. The third point, internal variability, relates to both how the climate system as a chaotic non-linear dynamical system is sensitive to small perturbations, and how modes of naturally occurring patterns of variability, e.g. NAO, evolve. Investigating the role of internal variability under non-stationary climate conditions, requires a large ensemble of climate simulations from a model with satisfactory representation of the variability patterns.

All of the above mentioned studies are based on model ensembles with few members of each model. This is partly due to the high computational resources associated with running a climate model for hundreds of years. This makes it difficult to adequately quantify the internal variability, and to separate it from the response to different external forcing applied in the future scenario or from the spread due to model uncertainty. In the multi-model ensemble approach of e.g. the CMIP3 and CMIP5, although they do contain over 100 members in total, each model is typically represented by a single-digit number of realisations. Such ensembles may therefore still not be able to answer the question of the role of natural variability.

With the relatively recent arrival of large ensembles such as the CCSM 1.4 62-member ensemble (Selten et al. 2004), the 17-member ECHAM5/MPI-OM ensemble (Sterl et al. 2008), the 50-member ensemble of CanESM2 (Kirchmeier-Young et al. 2016) and the 40-member CESM Large
Ensemble, from now on referred to as CESM-LE, (Kay et al. 2015), we now have better opportunities for separating natural variability and systematic effects of an external forcing. Of these four, the CESM-LE has the highest horizontal resolution ( $\sim 1$ degree, compared to $3.75,1.89$ and 2.81 for the other three). CESM-LE and CanESM2 also use a more recent emissions scenario (RCP 8.5, Riahi et al. 2011). By neglecting model uncertainty, all of the ensemble spread from a single-model ensemble originates from internal variability as it is represented in the specific model. In multi-model ensembles, the spread is a combination of model uncertainty and internal variability. In the CMIP5 ensemble, for example, the sampling of model uncertainty is quite arbitrary, as there is no systematic generation of perturbations of model process formulations in the ensemble. Furthermore, the part of the ensemble spread that represents natural variability is under-sampled, as there are few ensemble members per model.

In this study we apply the same MCAO index and two of the same areas as KBSO9 to 30 members $^{1}$ of the CESM-LE to investigate what processes condition future changes in MCAO. Apart from retreat of sea-ice and increase in surface and tropospheric temperatures, we also hypothesize that changes in the frequency of occurrence of circulation patterns may play a role (e.g. as in, Corti et al. 1999). We attempt to answer the following four questions: (1) how well does the CESM-LE represent MCAO compared to ERAInterim? (2) What are the projected future changes in MCAO and how does natural variability change? (3) How can these changes be attributed to different processes? and (4) Can any trends be explained by changes in circulation?

The structure of the article is as follows: the data and methods are presented in Sect. 2, including the definition of the MCAO index used. Section 3 presents the results and discussion, including model evaluation (Sect. 3.1), projected future changes and attribution (Sect. 3.2), and relation to circulation patterns (Sect. 3.3). Conclusions are presented in Sect. 4.

\section{Data and methods}

\subsection{Model and reanalysis data}

We retrieved data from members 1-30 of the CESM Large Ensemble (Kay et al. 2015) for the years 1920-2005 (historical greenhouse gas emissions) and 2006-2080 (RCP 8.5 scenario). The variables used are listed in Table 1 . All variables

\footnotetext{
${ }^{1}$ Between analysis and submission additional members became available, giving a current number of 40 members available. We used the first 30 members, i.e. there was no systematic selection.
} 
Table 1 Variables used from the CESM large ensemble

\begin{tabular}{ll}
\hline Variable & Description \\
\hline$f_{\text {ice }}$ & Sea-ice fraction \\
$p_{\mathrm{SL}}$ & Pressure at sea-level $(\mathrm{Pa})$ \\
$T_{500}, T_{850}$ & Atmospheric temperature at \\
$T_{S}$ & 500 and $850 \mathrm{hPa}(\mathrm{K})$ \\
\hline
\end{tabular}

were retrieved as daily means, while some of the analysis is performed aggregated to monthly means or percentiles. For validation we also retrieved the corresponding variables from the ERA-Interim reanalysis (Dee et al. 2011).

Potential temperature $\theta$ was calculated using $\theta=T\left(p_{0} / p\right)^{R / c_{p}}$, where $R / c_{p}=0.286$ and $p_{0}=1000 \mathrm{hPa}$.

\subsection{MCAO index}

We use an MCAO index $\mu$ from $K B 08$, but with potential temperatures at the $500 \mathrm{hPa}$ rather than $700 \mathrm{hPa}$ level:

$\mu=\frac{\theta_{\mathrm{SKT}}-\theta_{500}}{p_{\mathrm{SL}}-p_{500}}$

where $\theta_{\mathrm{SKT}}$ is the 'potential surface skin temperature', as in $K B 08$, by

$\theta_{\mathrm{SKT}}=T_{\mathrm{S}}\left(\frac{p_{0}}{p_{\mathrm{SL}}}\right)^{R / c_{p}}$

$\mu$ is a measure of the lower atmospheric static stability and is calculated at each grid point on daily time resolution. For more details about the index we refer to KB08. In their review of different PL detection criteria, Stoll et al. (2018) found $\theta_{\mathrm{SKT}}-\theta_{500}$ to be the most efficient criterium, but the performance of $\mu$ was very close (with a threshold including $90 \%$ of the PLs, the $\theta_{\text {SKT }}-\theta_{500}$ criterium excluded $88.5 \%$ non-PL cyclones, compared with $86.9 \%$ for the $K B 08$ criterium).

Bracegirdle and Gray (2008) argued for using the $700 \mathrm{hPa}$ level due to the high diabatically induced vertical motion around this level in many Nordic seas polar low case studies, and stated that the $500 \mathrm{hPa}$ level may be too far above the boundary layer to detect the relevant air-sea temperature difference. On the other hand, Stoll et al. (2018) found that using the potential temperature at the $500 \mathrm{hPa}$ level more efficiently filters out non-PL cyclones. They also noted that Bracegirdle and Gray (2008) used a smaller database of only 58 cases, consisting of both PLs and weaker cyclones. The difference between SST and the temperature at $500 \mathrm{hPa}$ is also routinely used for polar low forecasting at the Norwegian Meteorological Institute. Additionally, because daily

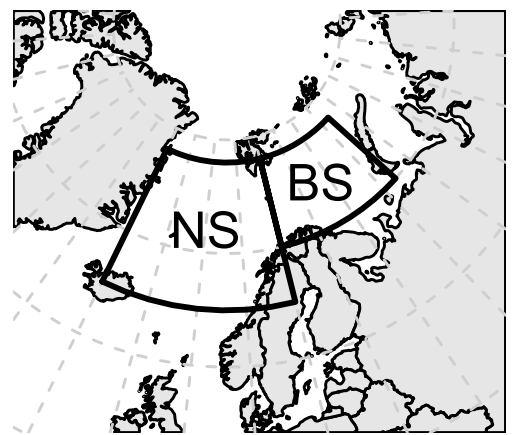

Fig. 1 Map showing the two regions of interest

data from CESM-LE for the full period 1920-2080 were only available at a few pressure levels $(850,500,200$ and 10 $\mathrm{hPa}$ ), we could not choose $700 \mathrm{hPa}$ directly, so we settled on $500 \mathrm{hPa}$. However, for comparison we also performed the analysis based on potential temperature at $700 \mathrm{hPa}$ interpolated from 500 and $850 \mathrm{hPa}$. We focus particularly on two areas, shown in Fig. 1, which are the same as in KBSO9:

1. Nordic Seas (NS): $20^{\circ} \mathrm{W}-20^{\circ} \mathrm{E}, 65^{\circ} \mathrm{N}-78^{\circ} \mathrm{N}$ (consisting of the Greenland, Iceland, Norwegian Seas, sometimes referred to as the GIN Seas).

2. Barents Sea (BS): $20^{\circ} \mathrm{E}-54^{\circ} \mathrm{E}, 70^{\circ} \mathrm{N}-78^{\circ} \mathrm{N}$.

As in Kolstad (2011), grid points with a surface skin temperature below $-1.9^{\circ} \mathrm{C}$ were assumed to be covered with sea ice and not used. The remaining grid points were analysed either directly for daily values, or they were aggregated by taking the 90-percentiles of all available points within each area each month. These monthly time-series are from now on referred to as MCAOmon90p.

\subsection{Cluster analysis}

Following the method of Dawson et al. (2012) we applied a k-means clustering algorithm to diagnose occurrence of circulation patterns. Sea-level pressure anomalies were calculated relative to 1920-2005 climatology. The Euro-Atlantic area $90^{\circ} \mathrm{W}-50^{\circ} \mathrm{E}, 30^{\circ} \mathrm{N}-90^{\circ} \mathrm{N}$ was used. For the DJFM season and member 1 of the ensemble, the phase space was reduced by projecting onto the four leading principal components. The data was then analysed using k-means clustering to form four clusters. These were used as initial centroids for assigning daily DJFM data for all ensemble members. A filter was applied in order to only include periods with at least 3 consecutive days assigned to the same pattern, removing approximately $13.8 \%$ of the days. For each day the 90-percentile of the grid point values within each area (i.e. percentile in the longitude and latitude dimension) was calculated, giving a time series for each area. The 90-percentile 


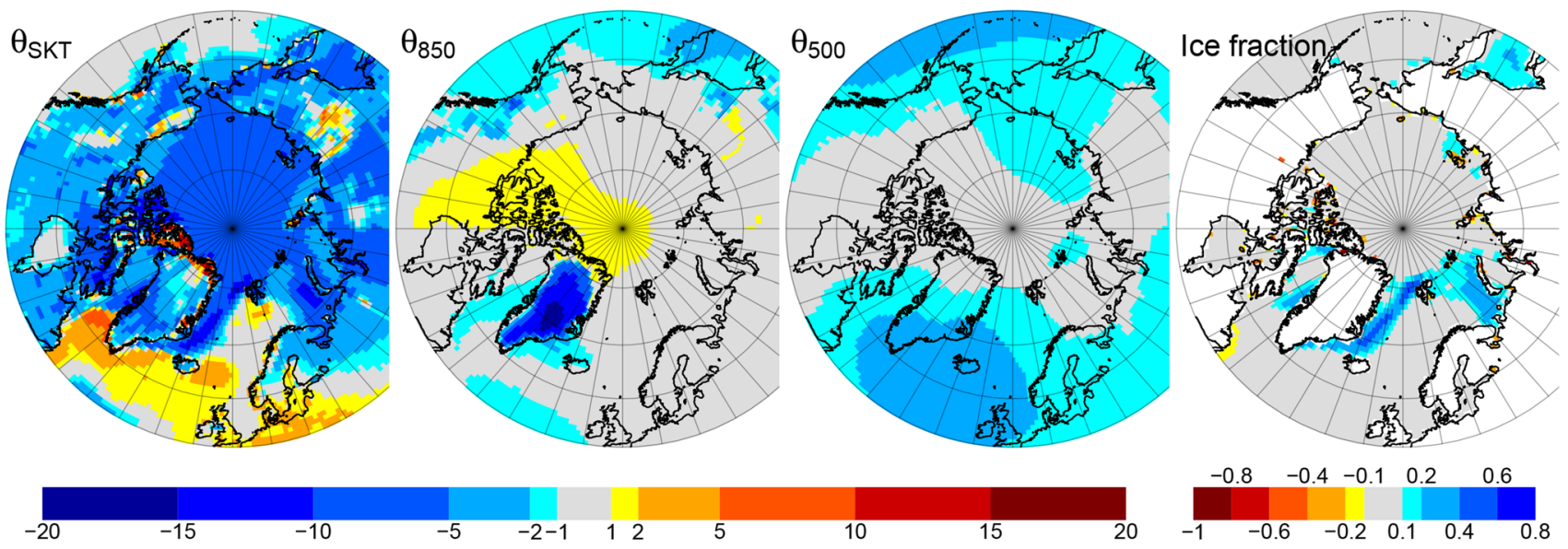

Fig. 2 Bias in CESM-LE ensemble mean against ERA-Interim, DJFM 1980-2005. From left to right: potential surface skin temperature, potential temperature at $850 \mathrm{hPa}$ and $500 \mathrm{hPa}$, and sea-ice fraction. Temperatures are in $\mathrm{K}$

was then taken again, in the time dimension, in order to select the days with the $10 \%$ highest (90-100 p) values. The cluster assignments for these days were then used to analyse the frequency of occurrence of the four circulation patterns.

\section{Results and discussion}

\subsection{Model evaluation}

\subsubsection{Temperature biases}

The biases of $\theta_{\mathrm{SKT}}$ and $\theta_{850}, \theta_{500}$ and ice fraction from CESM-LE, taken as the ensemble mean of DJFM climatology minus ERA-Interim, is presented in Fig. 2 (individual months in Fig. S1 in the supplementary material). The model ensemble has a large cold bias in the surface skin temperature, particularly over sea-ice. For CESM1, Park et al. (2014) found that these biases are mostly of radiative origin related to clouds. On the other hand, ERA-Interim is also known to have near-surface warm biases in the winter season (e.g. Serreze et al. 2012; Simmons and Poli 2015), so the CESM-LE cold bias presented here may in fact be a few degrees smaller in reality. ERA-Interim is also only one realisation of the climate, so the spread of any ensemble can be assumed to be greater. Since we use a single-model ensemble, the unavoidable systematic model errors, or climate biases, are not compensated in the way it could have been in a carefully designed multimodel ensemble. On the other hand, we have a clean estimate of internal, natural variability. The focus of this study is, however, on open water areas in the Nordic Seas and Barents Sea, over which both the $\theta_{\mathrm{SKT}}$ and $\theta_{850}$ biases are relatively small ( -1 to $+1 \mathrm{~K}$ are shown in grey). There is however a warm (cold) bias in
$\theta_{\mathrm{SKT}}\left(\theta_{500}\right)$ around Iceland, which leads to too high MCAO index values.

\subsubsection{Sea-ice concentration}

The fourth panel in Fig. 3 shows that the model ensemble has a positive bias in sea-ice fraction. This is particularly strong near the eastern coast of Greenland (the Fram Strait and the East-Greenland current) but weaker and over a larger area in the Barents Sea. This sea-ice bias also explains the surface skin temperature biases in these regions. One challenge lies in the strong observed sea-ice reduction in recent decades, especially in the Barents Sea. Li et al. (2017) attributed the strong sea-ice decline in the Barents Sea to enhanced oceanic heat transport due to strong regional internal variability, which is not sufficiently well represented in CMIP5 models. Onarheim and Årthun (2017) compared seaice concentration in CESM-LE and three other earth system models with observations over the Barents Sea. They found that internal variability can explain $72 \%$ of the trend in the past 30 years, if one assumes that the ensemble mean of CESM-LE represents the trend from external forcing correctly. Both references highlight the combination of forced response and internal variability needed to represent the observed sea-ice decline.

Swart et al. (2015) analysed the long-term trend in September Arctic sea ice and concluded that neither the CESMLE nor the CMIP5 ensembles systematically under-represent the sea-ice response to external forcing when accounting for internal variability. Sea-ice biases may however be larger on a regional scale, as can be seen in Fig. 3. While the northern hemispheric total sea-ice concentration follows ERA-Interim rather closely, a positive sea-ice bias in CESM-LE is more apparent in the smaller regions. In the future period the autumn minimum is extended, with the Barents Sea region 

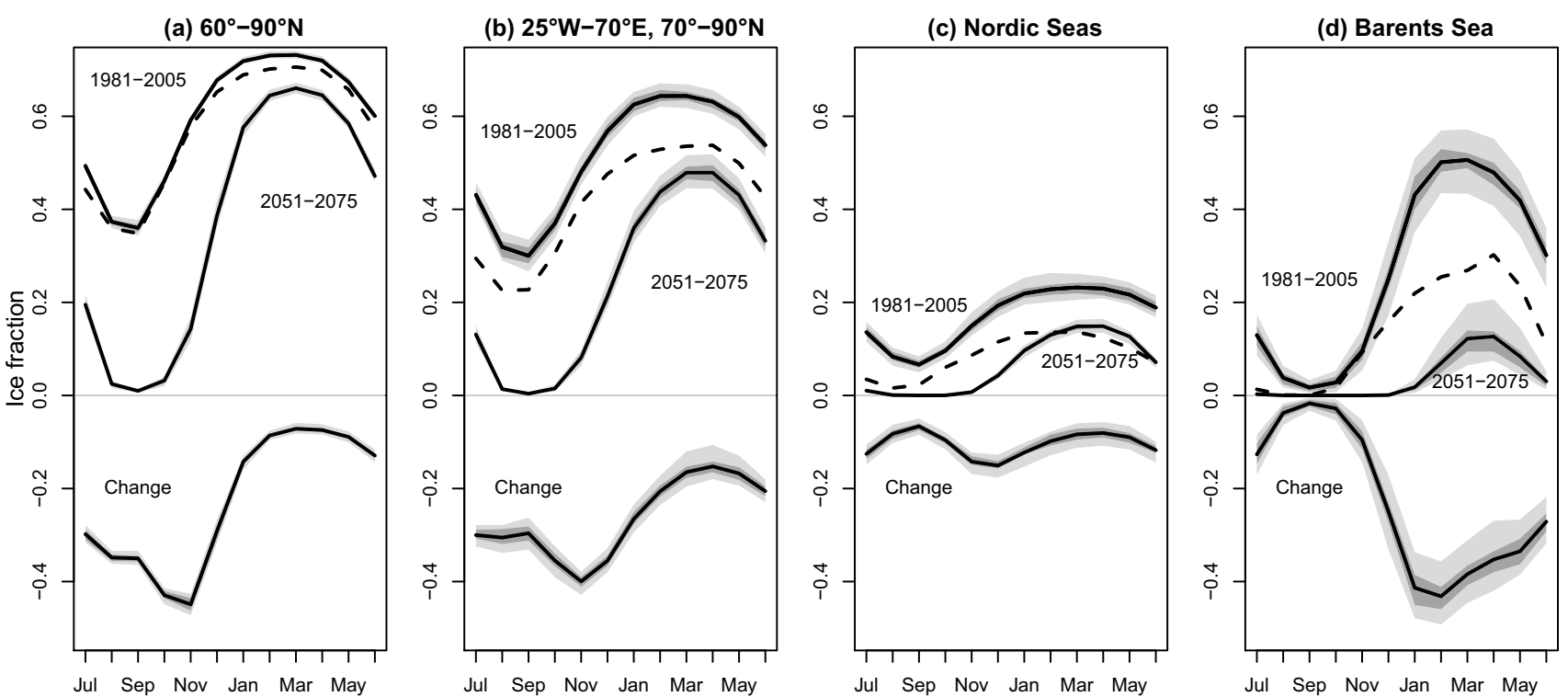

Fig. 3 Sea-ice concentration in CESM-LE for four different regions: a circumpolar north of $60^{\circ} \mathrm{N}$, b lon $25^{\circ} \mathrm{W}-70 \mathrm{E}$, lat $70^{\circ} \mathrm{N}-90^{\circ} \mathrm{N}$, c Nordic Seas, d Barents Sea. The ensemble mean for the periods 1981-2005 and 2051-2075 are shown by black lines, with the 5, 25,

75 and 95-percentiles of the ensemble in grey (the 25-year mean for each member was calculated first). The change between reference and future period is shown in the lower line. Data from ERA-Interim for 1981-2005 is shown as dashed lines

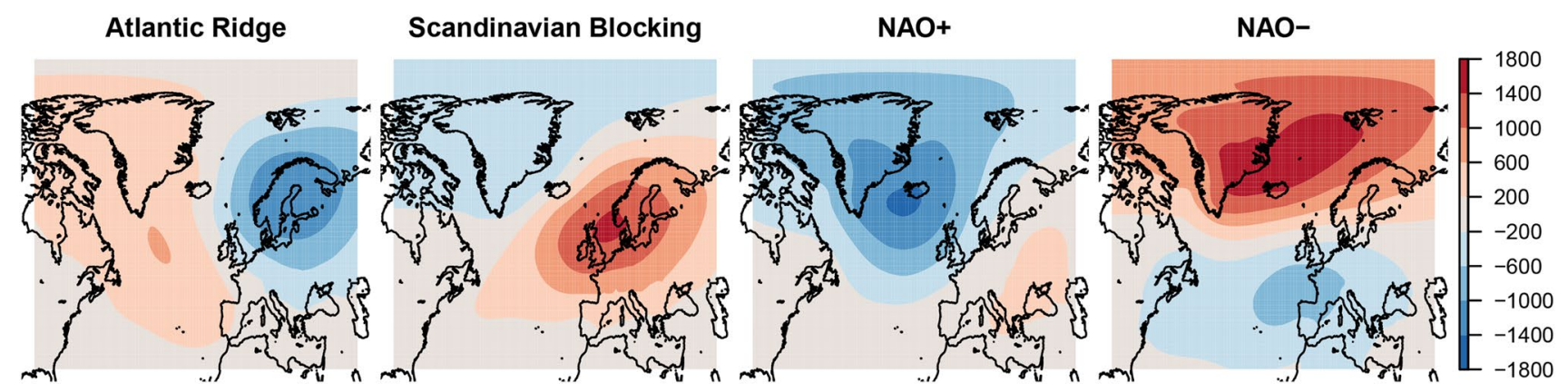

Fig. 4 Circulation patterns found using cluster analysis of $p_{\mathrm{SL}}$ anomaly (Pa). Positive anomalies are shown in red and negative in blue

becoming ice-free for half of the year and the peak being delayed by 1-2 months. The ensemble spread is largest for the Barents Sea, which is expected as it is also the smallest area.

\subsubsection{Circulation patterns}

The four clusters obtained from the k-means clustering method are shown in Fig. 4. These patterns are similar to those found in Dawson et al. (2012), although with distortions compared to re-analyses. We refer to the patterns using the same names, although we note that Davini and Cagnazzo (2014) caution that what is detected as the NAO from different CMIP5 models may actually come from different physical processes, so the implications under climate change may be different for different models.
Kim et al. (2017) found that the CESM-LE represents well the observed NAO on interannual to decadal time scale, but underrepresents the multidecadal variability. In terms of spatial structure, our NAO- pattern indicates too zonal storm tracks, as discussed in Day et al. (2018) and Zappa et al. (2013) for the CESM-LE and CMIP5 ensembles, respectively. Dawson et al. (2012) showed that the horizontal resolutions typically used in the CMIP5 ensemble may not be sufficient to reproduce observationally based circulation regimes.

\subsection{Projected future changes and attribution}

In the future period high values of the MCAO index, indicating a statically unstable troposphere, become less frequent. The spatial distribution of MCAO index values is shown 


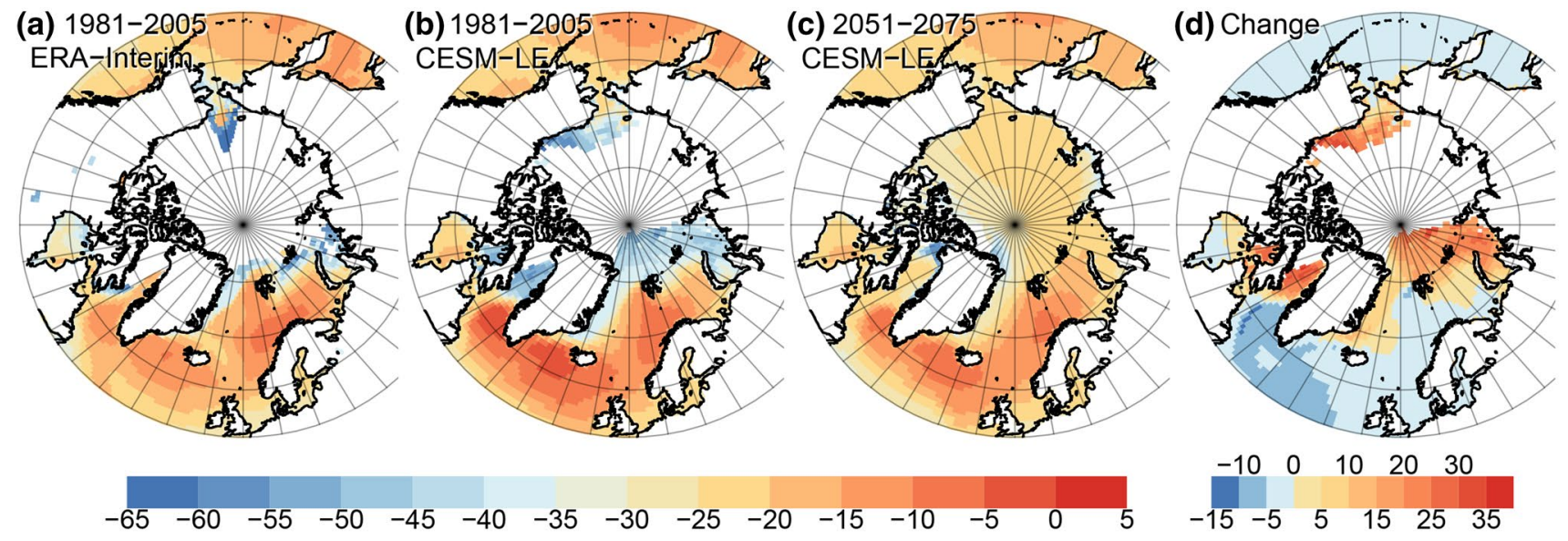

Fig. 5 90-percentiles of daily DJFM MCAO index values for each grid cell for two different time periods, 1981-2005 (left panel) and 20512075 (middle), as well as the difference (right)

in Fig. 5. Here the 90-percentile is estimated separately from the time series of each grid cell and model ensemble member, and then averaged over all ensemble members. Areas of high values are located around the southern tip of Greenland as well as between the Norwegian mainland and Svalbard. The values from CESM-LE are higher than those from ERA-Interim due to the temperature biases discussed in Sect. 3.1.1.

There are two main competing mechanisms driving the future changes in different areas: first, over open water, there is an increase in the tropospheric temperature which is larger than the SST increase and therefore increases the static stability (reduces the MCAO index values). This is strongest in the North-Atlantic ocean, but apparent in the Pacific ocean as well. A particularly strong signal is found south of Greenland, where a weakening Atlantic Meridional Overturning Circulation leads to a much smaller increase in SST as discussed in Kolstad and Bracegirdle (2008). Second, there is a decrease in sea-ice concentration (Fig. 3), which enables higher frequency of occurrence of MCAO over new areas with open water.

Separating the statistics into different months, Fig. 6 shows the ensemble mean trend in the MCAO index as well as trends of SST, $\theta_{500}$ and ice fraction. (The change in mean $p_{\mathrm{SL}}$ corresponds to an MCAO index change of less than $1 \%$ and is not shown.) To select days relevant for polar lows, we apply a threshold of $-20 \mathrm{~K} / \mathrm{bar}$. This value is the 10-percentile value of the MCAO index of PLs in Stoll et al. (2018), i.e. $90 \%$ of all PLs in that study occur when the MCAO index is above that value. We then select only $10 \%$ of the days - the ones with largest area above the threshold. This is done for each month and member separately, so that there are on average 3 days per month from each member. There are naturally months with no days as well as months with more than 10 days selected due to persistent circulation favouring MCAO. For each selected day the regional mean of the SST, $\theta_{500}$ and ice fraction is calculated, and the timeseries of the ensemble mean is shown in Fig. 6.

In both regions, $\theta_{500}$ shows a smaller warming in January and February than in December and March. In the Nordic Seas, this in combination with the weak SST increase in December and January, means that these two months have a stronger decline in MCAO index. An effect of this is the future peak of the strong MCAO season being shifted from January and more towards February in the Nordic Seas.

While Nov-Jan shows a stronger MCAO decrease than Feb-Apr in the Nordic Seas, the results are the opposite for the Barents Sea. There, the start of the freeze-up season is delayed month by month, accompanied by a gradually increasing SST. The lower temperatures and larger seasonal variation of sea ice in Barents Sea (cf. Fig. 3) also means that the SST trends can be stronger in December there. The large BS SST increases counteract the increase in $\theta_{500}$, resulting in a smaller decrease in the MCAO index in the beginning of the winter season.

Interestingly, the months with the largest reduction in sea-ice cover are also the ones with the largest decrease in MCAO index. While this may sound contradictory to the earlier statement that MCAO values increase in areas of melting sea-ice, both are in fact true. Starting out from very low surface temperatures over ice, the MCAO index increases locally as the ice melts, but with Cold-Air Outbreaks also being dependent on the cold extremes formed over sea-ice areas, the regional warming indicated by strong ice melt may also form fewer cold air masses.

The results are not very sensitive to the choice of tropospheric level. When using the $700 \mathrm{hPa}$ level (interpolated from 500 to $850 \mathrm{hPa}$ ), instead of $500 \mathrm{hPa}$, to calculate the MCAO index, the results look similar (not shown), with the exception that the $\mathrm{T}_{850}$ increase is even stronger in 

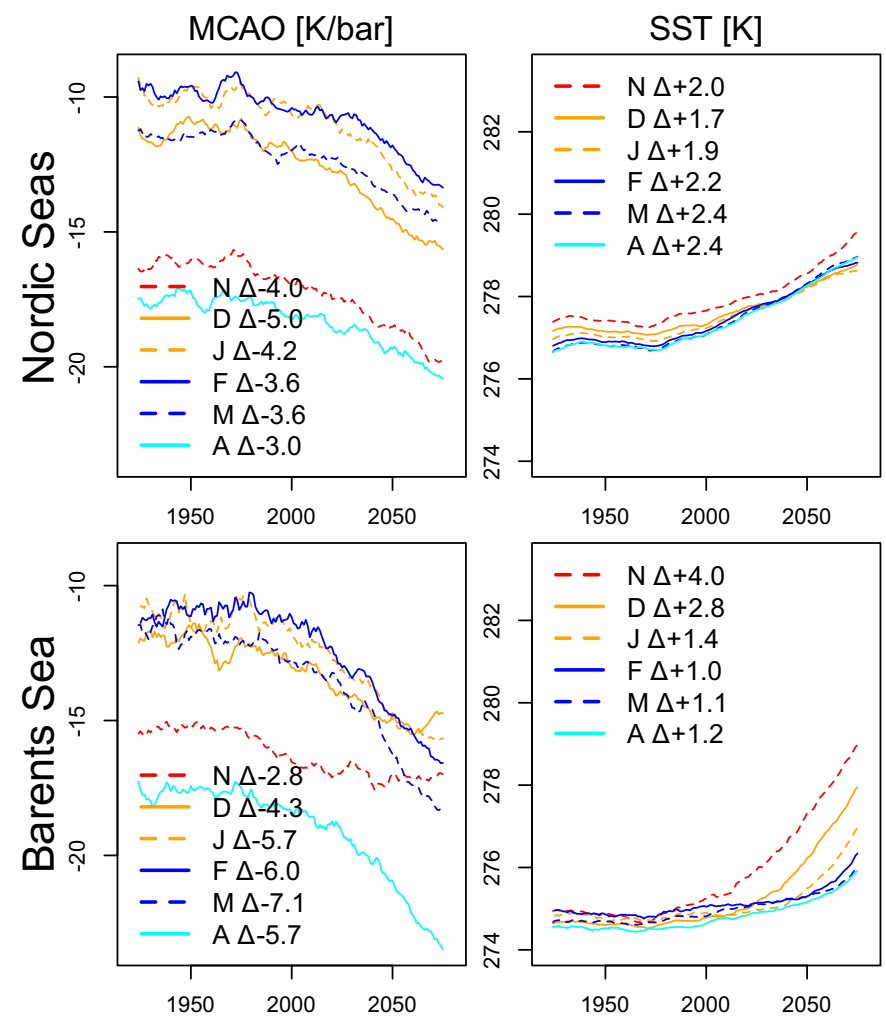

Fig. 6 Time series of (from left to right) the MCAO index, sea surface temperature, potential temperature at $500 \mathrm{hPa}$, and sea-ice fraction. Ensemble mean 10-year moving averages are shown, with different lines for different months (Nov-Apr). Years are shown on the $\mathrm{x}$ axes. The top panels show results for the Nordic Seas and the bottom panels show results for the Barents Sea. Only days with the $10 \%$ largest area above the $-20 \mathrm{~K} / \mathrm{bar}$ threshold are used. For MCAO, SST

December, and gradually smaller in the later months. This leads to a more pronounced December MCAO decrease.

As an overview of the change in mean climatology, the vertical structure of the tropospheric warming is presented in Fig. 7. This is done without any MCAO-specific selection because data on vertical levels is only available on monthly time resolution. We can clearly see the near-surface warming in the winter months, commonly referred to as Arctic amplification, which is found in reanalyses (Simmons and Poli 2015) as well as climate models (Pithan and Mauritsen 2014; Laîné et al. 2016). Pithan and Mauritsen (2014) showed that the annual Arctic amplification is dominated by the temperature lapse-rate feedback, while the surface albedo feedback dominates during summer.

In addition to the pattern of surface warming, we see a mid-tropospheric autumn maximum and a spring minimum. Laîné et al. (2016) found a similar pattern of tropospheric temperature increase when comparing CMIP5 model runs for years 1981-2000 and 2081-2100 using the RCP4.5 scenario, although in our analysis of CESMLE, the peak appears one month later (September rather
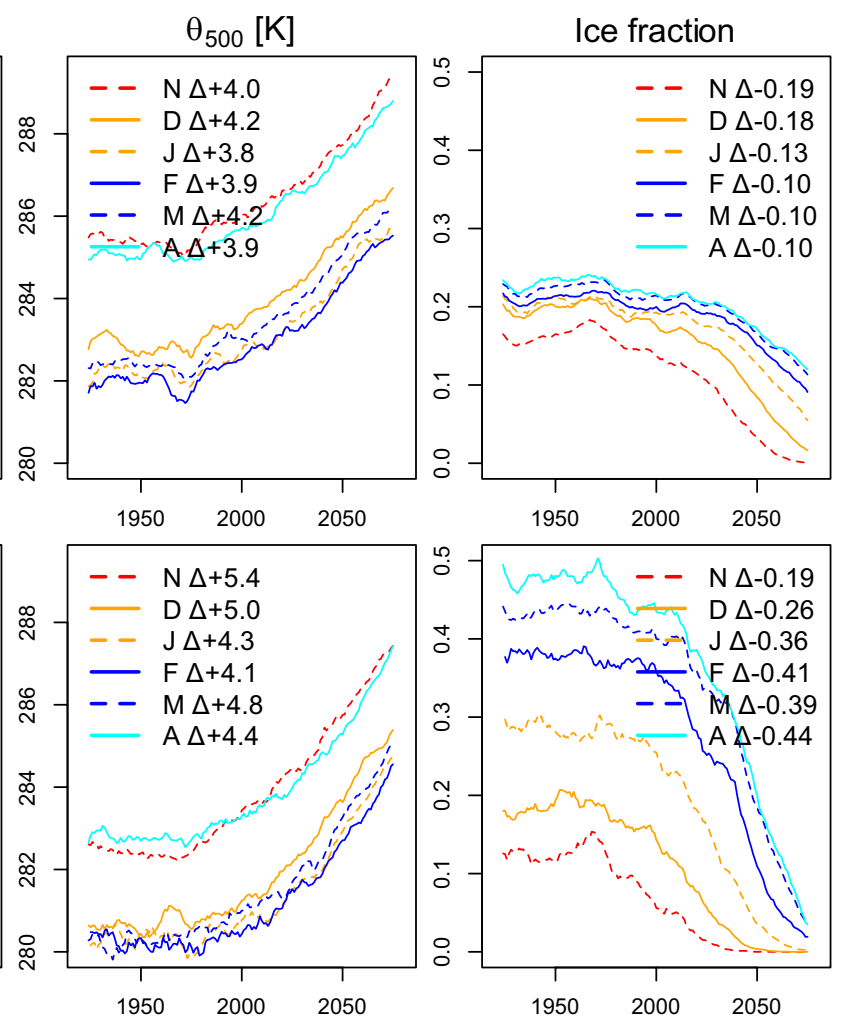

and $\theta_{500}$, values are averaged over open water grid points, while ice fraction shows the coverage in the whole region. The numerical values of change is shown $(\Delta)$, estimated as linear trends for the whole 161-year period. Top and bottom panels have the same axes, and the SST and $\theta_{500}$ panels have equal vertical distance, to highlight that changes in $\theta_{500}$ are greater

than August). The timing of this maximum follows the peak in SST change, but contrasts the change in surface temperature, which peaks in December-January, and has its minimum in July. In the future, when the freeze-up season starts later (Fig. 3), heat fluxes from the ocean play a role also in the early winter months. Since the temperature change (Fig. 7) at the $500 \mathrm{hPa}$ level is steeper throughout the winter than the SST, illustrated by the December and February values marked as dots, the impact on the MCAO index is different for different months (Fig. 6).

We then separate into areas of open water, ice only, and melting ice; shown in Fig. 7b-d, respectively. Over open water, the strong near-surface warming is gone, and the $500 \mathrm{hPa}$ Dec-Feb change is comparable to the Dec-Feb SST change, giving no change in the (mean) MCAO index values. In contrast, over melting ice (d) the Dec-Feb change is more than twice as large, 4.2-3.1 at the highlighted dots compared to $0.95-0.53$ for the SST.

It is worth noting that even with the strong near-surface warming, these levels are still around $15-20 \mathrm{~K}$ colder than 
(a) CESM-LE, NA, all areas

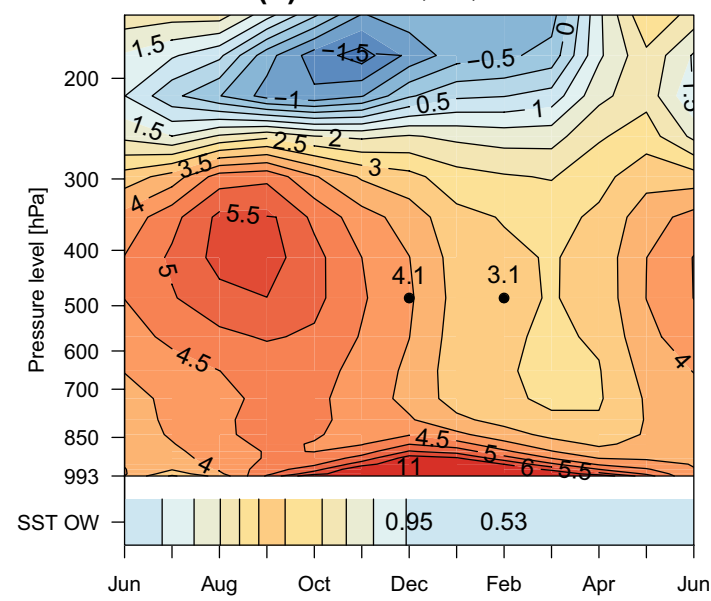

(c) CESM-LE, NA, ice only
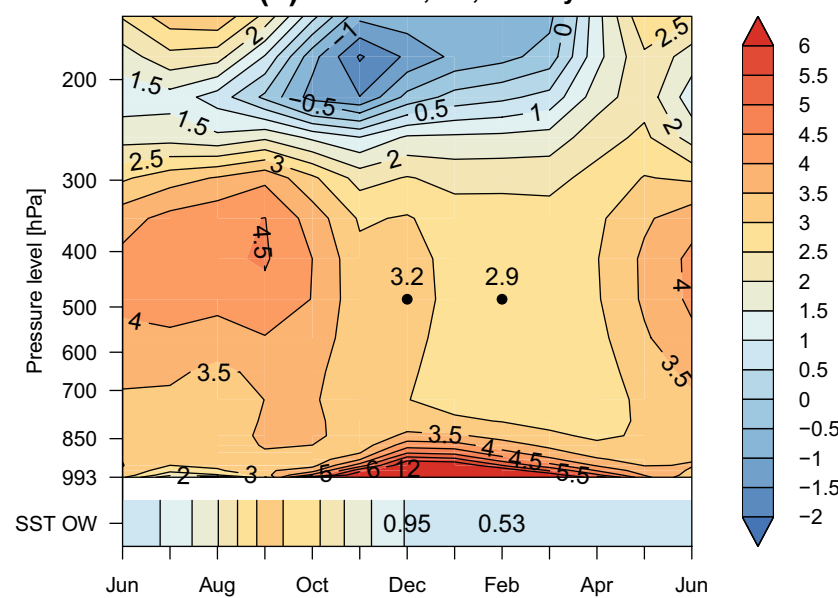

Fig. 7 Ensemble mean temperature change from 1981-2005 to 20512075. The tropospheric potential temperature at different pressure levels are shown on the vertical axis, with changes in SST over open water (grid points above $272 \mathrm{~K}$ ) plotted below (same in all four panels). Changes for December and February are highlighted at $500 \mathrm{hPa}$ as well as the largest near-surface temperature change. The selected

the SST, which will naturally remain the source of heat for MCAO.

Figure 8 shows changes in different quantiles of the MCAO index. In the Nordic Seas the MCAO index decreases more in December and January than later in the winter, leading to a shift in the timing of the peak from January to February. In both regions the higher quantiles decrease more than the 0.75 quantile. As discussed above this is mainly due to the increase of SST and decrease of sea ice in the beginning of the season. In the Barents Sea the reduction is larger in the end of the season (except for the 0.999 quantile). Using a single-model ensemble makes it easier to draw conclusions on a changing seasonal cycle of MCAO, compared to a multi-model ensemble, when different models have very different representation of for example sea-ice.

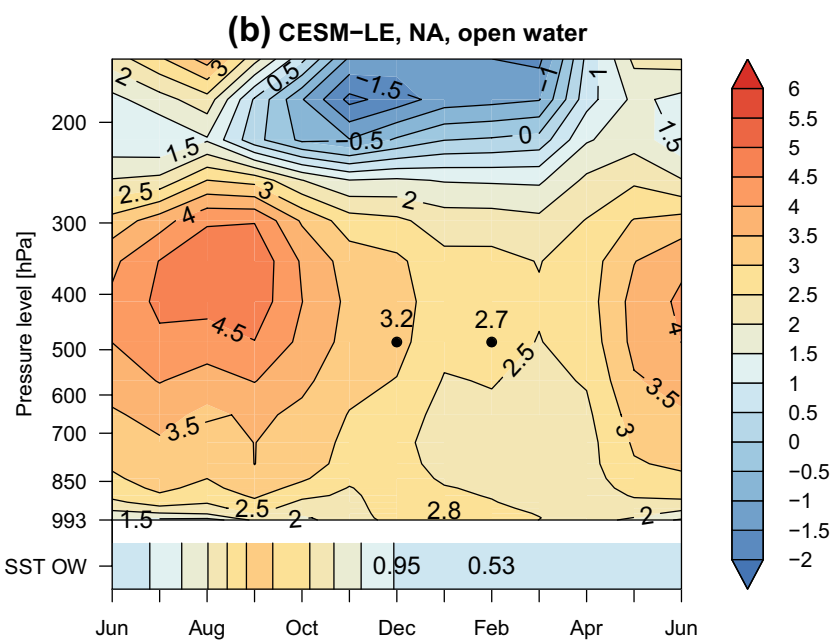

(d) CESM-LE, NA, melting ice

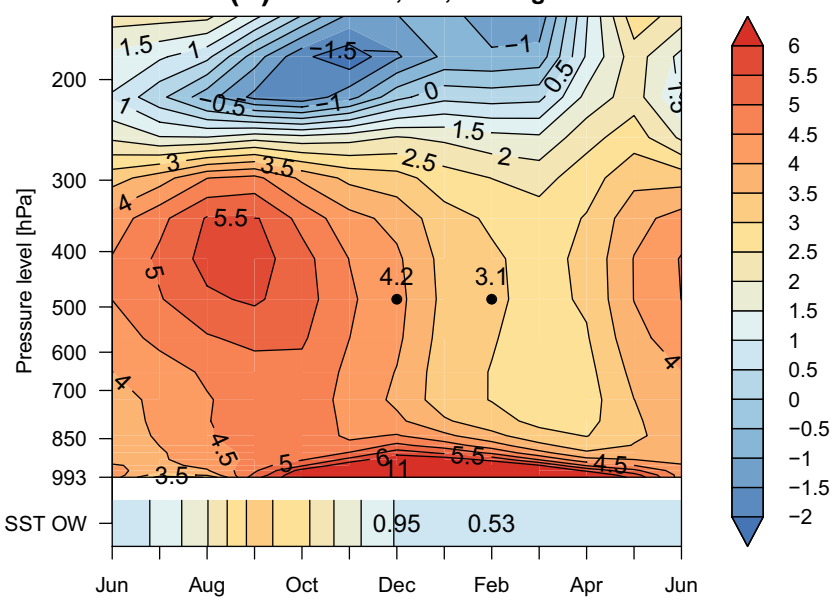

region is a North Atlantic/Arctic area with longitudes $25^{\circ} \mathrm{W}-70^{\circ} \mathrm{E}$ and latitudes $70^{\circ} \mathrm{N}-90^{\circ} \mathrm{N}$. a Ocean and sea-ice areas (as well as a few grid points of land). b, $\mathbf{c}$ Uses only areas with below/above $15 \%$ ice fraction in both time periods, while $\mathbf{d}$ uses areas that are changing from ice-covered to ice-free (15\% ice fraction threshold)

In order to relate the MCAO index to occurrence of polar lows, we again apply the threshold of $-20 \mathrm{~K} / \mathrm{bar}$. The number of days per month with at least one grid point with value exceeding this is shown in Fig. 9. Comparing the future period with the reference period, the Nordic Seas experiences a slightly shifted peak in the future, as expected from Fig. 8. Changes in the Barents Sea are much smaller than in the Nordic Seas, but statistically significant only for non-peak months, indicating a possible shortening of the PL season in the future. The advantage of a single-model ensemble in this case is that the ensemble spread shown in Fig. 9 is only from the model system's representation of internal variability.

The change in variability is quantified by taking the IQR (interquartile range, $p_{75}-p_{25}$ ) of the future period divided by the IQR for the historical period. The results are 
Fig. 8 MCAO index values at different quantiles $(\mathrm{a}=0.999, \mathrm{~b}$ $=0.99, \mathrm{c}=0.95, \mathrm{~d}=0.90, \mathrm{e}=$ 0.75). All open water grid point values for all ensemble members are used. Years 1981-2005 are shown in solid lines and 2051-2075 in dashed lines
Nordic Seas

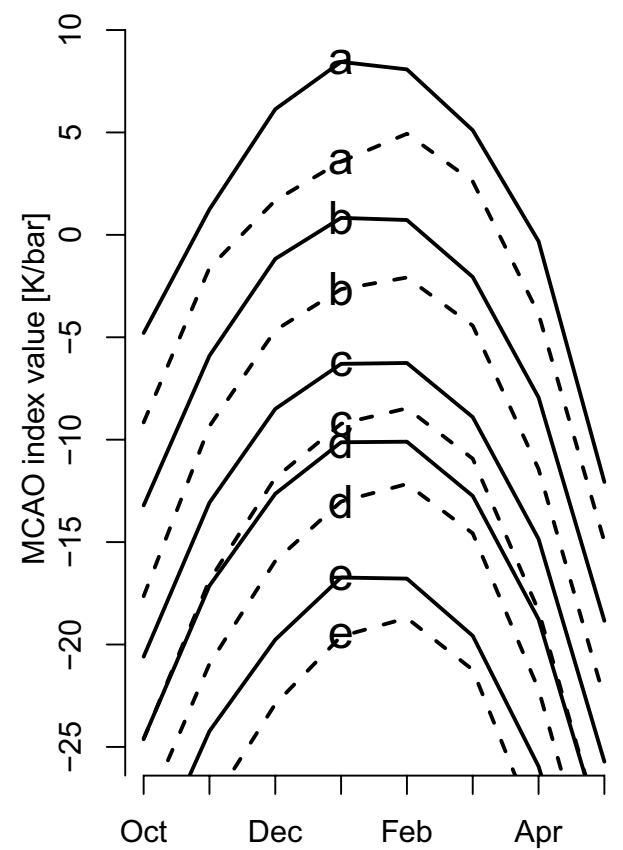

Barents Sea

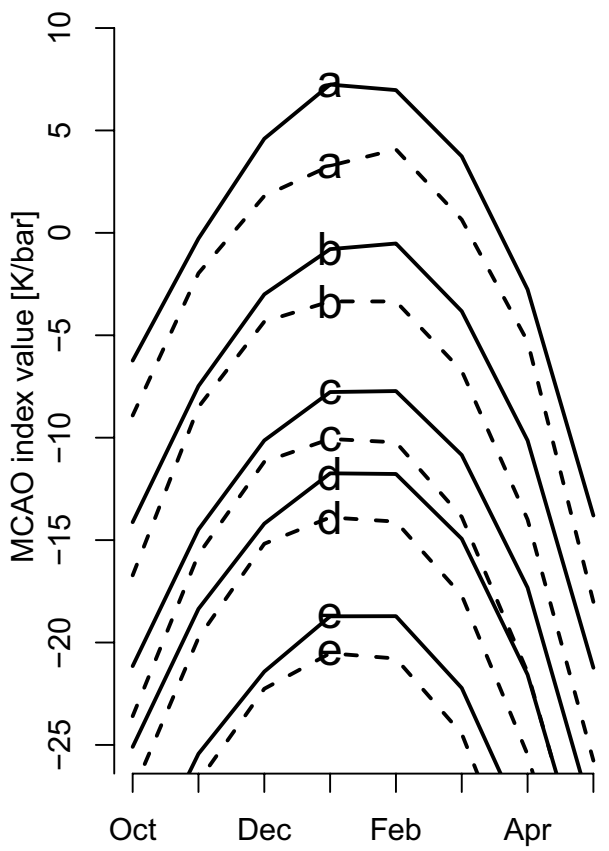

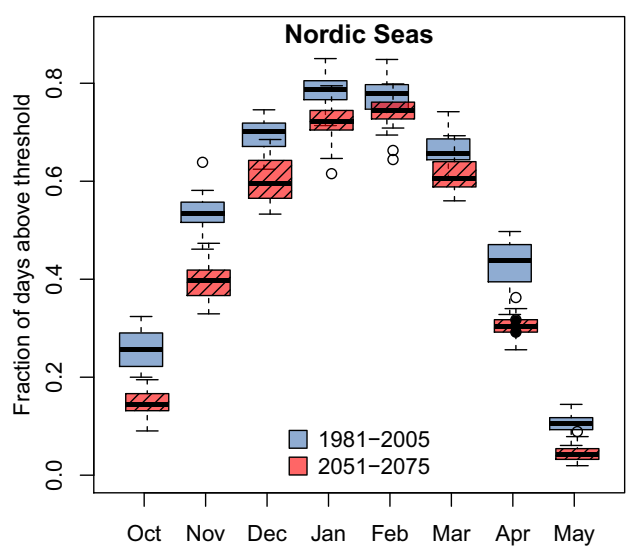

Fig. 9 Fraction of days with at least one grid point with value above $-20 \mathrm{~K} / \mathrm{bar}$ for the Nordic Seas (left) and the Barents Sea (right). Two periods are compared, years 1981-2005 (blue) and 2051-2075 (red). First the mean number of days exceeding the threshold was calculated for each month. Then the mean was taken for each ensemble mem-

presented in Table 2. Not surprisingly, the variability in ice fraction decreases the most, with the Barents Sea region having all members reach total or near ice-free conditions in December and January, together with an accompanying SST variability increase. Most variables do not show a significant change in variability. The variability of frequency of potential polar low days, i.e. at least one grid point has a value above $-20 \mathrm{~K} / \mathrm{bar}$, is increased in the Nordic Seas.

A possible limitation of this study is that the two focus areas are based on favorable conditions for polar low

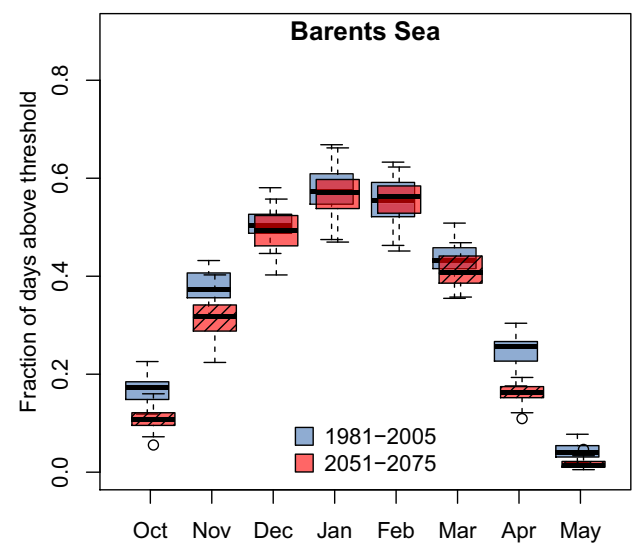

ber and period, so that the box heights are indicative of the spread between the different members. Distributions that are statistically significantly different ( $p<0.05$ from t-test) relative to the reference period are hatched

development in the present-day. With sea ice projected to retreat one could also argue that it could be worthwhile to perform similar analyses in other areas, such as the Kara Sea. The future 90-percentiles shown in Fig. 5 indicate that although the values increase considerably in the Kara Sea, they are still lower than in the Nordic and Barents Seas. 
Table 2 Change in interquartile range, future period IQR divided by reference period $\mathrm{IQR}$, shown in percent, for different parameters

\begin{tabular}{|c|c|c|c|c|c|c|c|c|}
\hline \multirow[t]{2}{*}{ Parameters } & \multicolumn{4}{|c|}{ Nordic Seas } & \multicolumn{4}{|c|}{ Barents Sea } \\
\hline & Dec & Jan & $\mathrm{Feb}$ & Mar & Dec & Jan & $\mathrm{Feb}$ & Mar \\
\hline MCAOmon90p & $(-2)$ & $(-1)$ & $(-12)$ & $(-3)$ & $(+2)$ & $(-7)$ & $(-10)$ & $(-11)$ \\
\hline $\begin{array}{l}\text { MCAO index, fraction } \\
\text { of days }>-20 \mathrm{~K} / \mathrm{bar}\end{array}$ & $(+12)$ & +24 & +14 & $( \pm 0)$ & $(+5)$ & $(+18)$ & $(+6)$ & $( \pm 0)$ \\
\hline $\mathrm{T}_{500}$ & $(-11)$ & $(+25)$ & $(+2)$ & $(+2)$ & $(+10)$ & $(-4)$ & $(+13)$ & $(+11)$ \\
\hline Ice fraction & $-\mathbf{3 0}$ & -16 & -29 & -27 & -100 & -97 & -65 & -47 \\
\hline SST & $(-16)$ & $(-9)$ & $(+3)$ & $(+6)$ & +60 & +67 & $(+5)$ & +15 \\
\hline
\end{tabular}

IQR is first calculated for each member and period. Then the 30 values for the reference period are compared to the 30 values for the future period. The ensemble median of $100 \times\left(\mathrm{IQR}_{\text {fut }} / \mathrm{IQR}_{\mathrm{ref}}-1\right)$ is shown in the table. Significance is tested by a two-sided t-test. Changes with $p<0.05$ are marked in bold, while nonsignificant changes are within parentheses

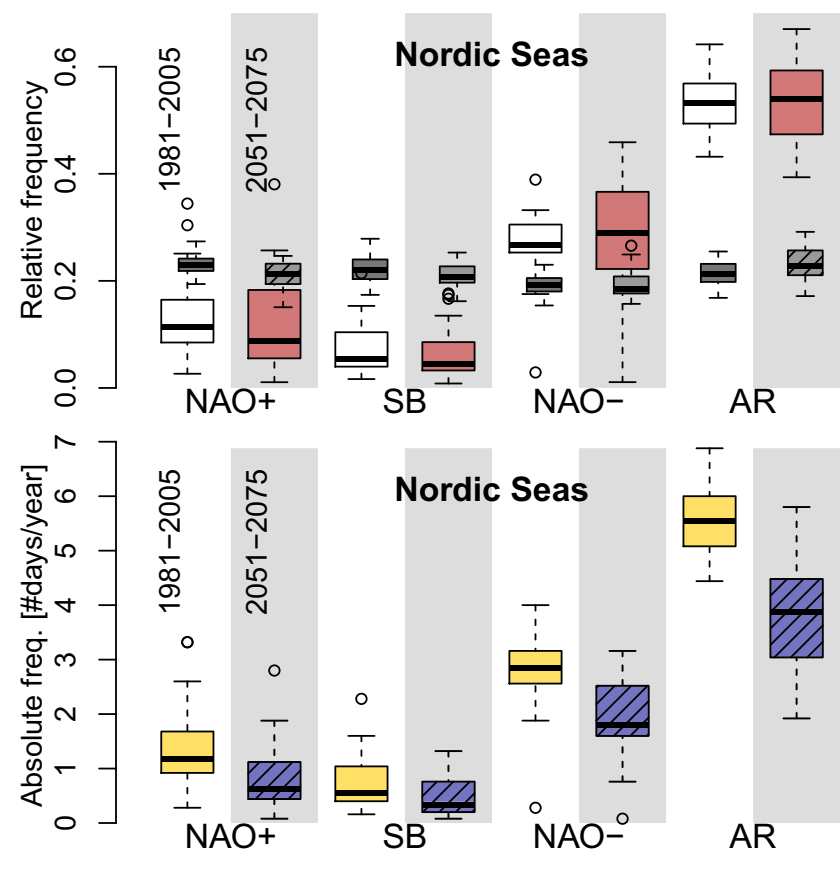

Fig. 10 Relative (top panels) and absolute (bottom panels) frequency of occurrence of the four regimes for days above 90-percentile MCAO in the Nordic Seas (left) and Barents Sea (right). The two periods are DJFM for 1981-2005 and 2051-2075. Also shown is the overall frequency of occurrence for each regime without MCAO

\subsection{MCAO in relation to circulation patterns}

To assess if changes in circulation can explain changes in the MCAO index value, we selected days with high MCAO index values and compared the distribution of circulation during those days. The cluster analysis provided daily time-series of cluster assignments for each of the 30 ensemble members. For the two areas and each member, days with the $10 \%$ highest MCAO index values were selected. The distribution of circulation patterns for these days is shown in Fig. 10. Mallet et al. (2013) compares the occurrences of these weather patterns in six different PL
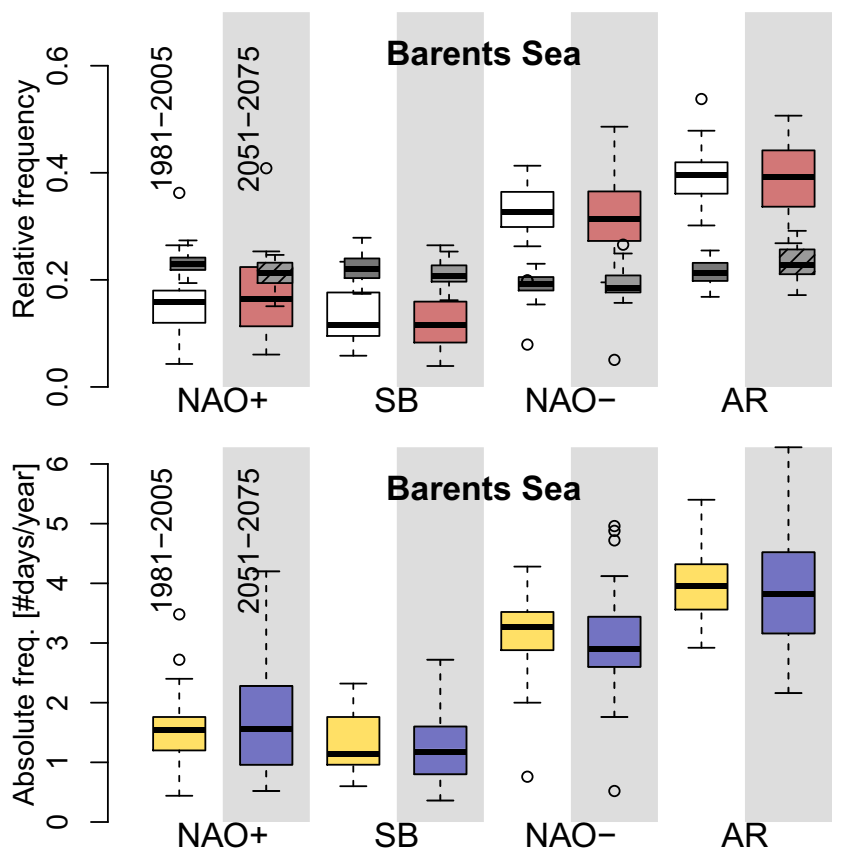

selection (top panels, grey boxes). Values are averaged for each member separately, so that the boxes show the spread between members and not within members. Significant changes $(p<0.05$ from twosided t-tests) are marked with hatching

articles and gives a detailed explanation of how the different patterns favour polar low development. Our results are similar in that the AR pattern gives the highest occurrence when selecting days of high MCAO index values. Looking at the changes in occurrence for all DJFM days (not only days above the 90-percentile of MCAO index) the change is significant for the NAO+ and AR patterns (grey boxes in Fig. 10), with p-values 0.0037 and 0.0130, respectively. The timeline of frequencies during the period 1920-2080 (Fig. 11) however indicates that the detected $\mathrm{NAO}+$ change may be sensitive to the selection of periods. 
Fig. 11 Frequency of occurrence of the four regimes during DJFM 1920-2080. 30-year moving averages are shown for each individual member in grey and the ensemble mean in black
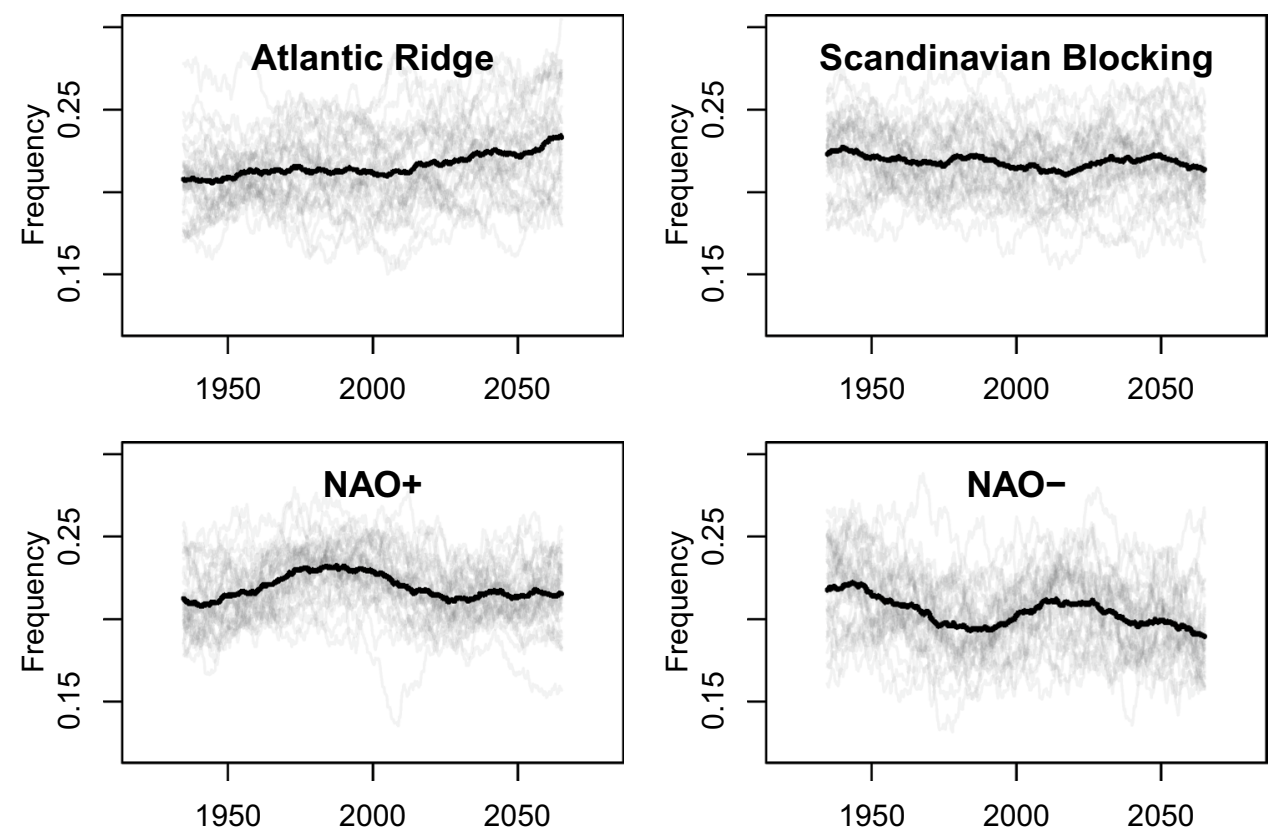

We initially performed the analysis using $Z_{500}$ anomalies instead of $p_{S L}$, but due to changes over time in the mean $Z_{500}$ field this would ideally require a more sophisticated detrending approach. Using a simple linear detrending we nevertheless found a similar increase in the frequency of the AR pattern in the 21 st century.

For days with high MCAO index, the relative frequency changes are not statistically significant for any of the patterns (comparing white and red boxes in the top panels of Fig. 10), although there is a future increase in ensemble spread. When taking into account that the number of days with high MCAO index values decreases in the future (bottom panels in Fig. 10) it is clear that changes in circulation can only play a minor role. For example, despite AR (the pattern of highest occurrence of high MCAO values) increasing in the future period (grey boxes in Fig. 10), the number of days above the MCAO 90-percentile sees a large decrease in the Nordic Seas. In the Barents Sea however, there are no significant changes.

Mallet et al. (2017) found that circulation patterns give a reduced influence on the static stability in the future, as sea-ice retreat reduces the variability. The historical link between circulation pattern and static stability (and thus as a proxy for polar lows) is therefore not the same in the future, posing a challenge when using it as part of a statistical downscaling approach. In agreement with our results, they also found that the strongest stability index decrease appeared for the patterns associated with high index values (NAO and AR). They also found very small changes in the Barents Sea compared to the Norwegian Sea.

\section{Conclusions}

The index of Marine Cold-Air Outbreaks can serve as a large-scale diagnosis of conditions associated with the occurrence of polar lows. We applied an MCAO index to 30 members of the CESM Large Ensemble to investigate changes over the Nordic Seas and Barents Seas.

Relative to ERA-Interim, the model ensemble has some biases, but for our domain of interest the biases were found to be small over open water, which was the focus of the study. The model system in general has a positive seaice concentration bias ice during the ERA-Interim period. Because this may also affect atmospheric fields, this may be a limitation to the relevance of the results in this study, particularly in the Barents Sea where the sea-ice bias and future sea-ice loss is largest. We have therefore focused more on the signs and magnitudes of the changes than the actual values. We conclude as follows:

- The CESM-LE shows an overall increase in tropospheric temperature which is stronger than the surface skin temperature increase, leading to a tropospheric static stability increase and a reduction in MCAO index values.

- In areas of strong sea-ice melt, the MCAO index increases, resulting in a northward shift of MCAO. This is consistent with other studies such as Kolstad and Bracegirdle (2008) and Zahn and von Storch (2010).

- A threshold of $-20 \mathrm{~K} / \mathrm{bar}$ was applied to select polar low-relevant days. Using this threshold there were sta- 
tistically significant future reductions in the Nordic Seas for all months (Oct-May), with Nov-Jan exhibiting stronger reduction than $\mathrm{Feb}-\mathrm{Apr}$.

- The Nordic Seas MCAO — and potentially polar lowseason is therefore shortened and shifted, with a future peak in February instead of January.

- Despite the overall reduction of the MCAO index in the Barents Sea, the only statistically significant changes in the number of days above the threshold are during offpeak season. This is likely because the future sea-ice reduction enables MCAO over larger areas during the winter months. While the peak may remain, reductions during autumn and spring months however may shorten the polar low season in the Barents Sea.

- The fraction of days with MCAO index values above - $20 \mathrm{~K} / \mathrm{bar}$ shows increased variability in mid-winter in the Nordic Seas. The ice fraction has decreased variability for the December-March season in both regions. SST variability increases in the Barents Sea, particularly in December-January.

- Our k-means clustering method shows a small but statistically significant increase in the Atlantic Ridge-like circulation regime, but failed to yield any significant implications to the MCAO, and potentially polar low occurrence. The changes were completely dominated by changes in temperatures and sea ice.

In the end, polar lows are too small to be resolved by coarse global models, and the MCAO index serves only as a proxy for favorable conditions for polar low development. Current ongoing work therefore applies dynamical downscaling and a cyclone tracking algorithm to the CESM-LE, in order to assess to what extent the MCAO seasonality change also implies a change in polar low seasonality.

Acknowledgements This study was funded by the Norwegian Research Council project EVA-Earth system modelling of climate Variations in the Anthropocene, Grant number 229771 under the KLIMAFORSK programme. We acknowledge the CESM Large Ensemble Community Project and supercomputing resources provided by NSF/CISL/ Yellowstone. We would also like to thank the team at MPI-MET for the data processing tool Climate Data Operators, CDO (http://www.mpime t.mpg.de/cdo), as well as Charlie Zender at UCI for NetCDF Operators, NCO (http://nco.sourceforge.net/nco.html), which have made processing large amounts of climate data much easier. We also thank the three anonymous reviewers for their constructive comments.

OpenAccess This article is distributed under the terms of the Creative Commons Attribution 4.0 International License (http://creativeco mmons.org/licenses/by/4.0/), which permits unrestricted use, distribution, and reproduction in any medium, provided you give appropriate credit to the original author(s) and the source, provide a link to the Creative Commons license, and indicate if changes were made.

\section{References}

Bracegirdle TJ, Gray SL (2008) An objective climatology of the dynamical forcing of polar lows in the Nordic seas. Int J Climatol 28(14):1903-1919. https://doi.org/10.1002/joc.1686

Businger S (1985) The synoptic climatology of polar low outbreaks. Tellus A 37(5):419-432

Corti S, Molteni F, Palmer TN (1999) Signature of recent climate change in frequencies of natural atmospheric circulation regimes. Nature 398(6730):799-802. https://doi. org/10.1038/19745

Davini P, Cagnazzo C (2014) On the misinterpretation of the North Atlantic Oscillation in CMIP5 models. Clim Dyn 43(5-6):14971511. https://doi.org/10.1007/s00382-013-1970-y

Dawson A, Palmer TN, Corti S (2012) Simulating regime structures in weather and climate prediction models. Geophy Res Lett 39(21). https://doi.org/10.1029/2012GL053284

Day JJ, Holland MM, Hodges KI (2018) Seasonal differences in the response of Arctic cyclones to climate change in CESM1. Clim Dyn 50(9):3885-3903. https://doi.org/10.1007/s0038 2-017-3767-x

Dee DP, Uppala SM, Simmons AJ, Berrisford P, Poli P, Kobayashi S, Andrae U, Balmaseda MA, Balsamo G, Bauer P, Bechtold P, Beljaars ACM, van de Berg L, Bidlot J, Bormann N, Delsol C, Dragani R, Fuentes M, Geer AJ, Haimberger L, Healy SB, Hersbach H, Hólm EV, Isaksen L, Kållberg P, Köhler M, Matricardi M, McNally AP, Monge-Sanz BM, Morcrette JJ, Park BK, Peubey C, de Rosnay P, Tavolato C, Thépaut JN, Vitart F (2011) The ERA-Interim reanalysis: configuration and performance of the data assimilation system. Q J R Meteorol Soc 137(656):553-597. https://doi.org/10.1002/qj.828

Emanuel KA, Rotunno R (1989) Polar lows as arctic hurricanes. Tellus A Dyn Meteorol Oceanogr 41(1):1-17. https://doi.org/10.3402/ tellusa.v41i1.11817

Harrold TW, Browning KA (1969) The polar low as a baroclinic disturbance. Q J R Meteorol Soc 95(406):710-723. https://doi. org/10.1002/qj.49709540605

Hawkins E, Sutton R (2009) The potential to narrow uncertainty in regional climate predictions. Bull Am Meteorol Soc 90(8):10951108. https://doi.org/10.1175/2009BAMS2607.1

Kay JE, Deser C, Phillips A, Mai A, Hannay C, Strand G, Arblaster JM, Bates SC, Danabasoglu G, Edwards J, Holland M, Kushner P, Lamarque JF, Lawrence D, Lindsay K, Middleton A, Munoz E, Neale R, Oleson K, Polvani L, Vertenstein M (2015) The community earth system model (CESM) large ensemble project: a community resource for studying climate change in the presence of internal climate variability. Bull Am Meteorol Soc 96(8):13331349. https://doi.org/10.1175/BAMS-D-13-00255.1

Kim WM, Yeager S, Chang P, Danabasoglu G (2017) Low-frequency North Atlantic climate variability in the community earth system model large ensemble. J Clim 31(2):787-813. https://doi. org/10.1175/JCLI-D-17-0193.1

Kirchmeier-Young MC, Zwiers FW, Gillett NP (2016) Attribution of extreme events in Arctic Sea ice extent. J Clim 30(2):553-571. https://doi.org/10.1175/JCLI-D-16-0412.1

Kolstad EW (2011) A global climatology of favourable conditions for polar lows. Q J R Meteorol Soc 137(660):1749-1761. https://doi. org/10.1002/qj.888

Kolstad EW, Bracegirdle TJ (2008) Marine Cold-Air Outbreaks in the future: an assessment of IPCC AR4 model results for the Northern Hemisphere. Clim Dyn 30(7-8):871-885. https://doi.org/10.1007/ s00382-007-0331-0

Kolstad EW, Bracegirdle TJ, Seierstad IA (2009) Marine Cold-Air Outbreaks in the North Atlantic: temporal distribution and 
associations with large-scale atmospheric circulation. Clim Dyn 33(2-3):187-197. https://doi.org/10.1007/s00382-008-0431-5

Kristjánsson JE, Barstad I, Aspelien T, Føre I, Godøy Ø, Hov Ø, Irvine E, Iversen T, Kolstad E, Nordeng TE,others (2011) The Norwegian IPY-THORPEX: polar lows and Arctic fronts during the 2008 Andøya campaign. Bull Am Meteorol Soc 92(11):1443. . https:// doi.org/10.1175/2011BAMS2901.1

Laîné A, Yoshimori M, Abe-Ouchi A (2016) Surface Arctic amplification factors in CMIP5 models: land and oceanic surfaces and seasonality. J Clim 29(9):3297-3316. https://doi.org/10.1175/ JCLI-D-15-0497.1

Li D, Zhang R, Knutson TR (2017) On the discrepancy between observed and CMIP5 multi-model simulated Barents Sea winter sea ice decline. Nat Commun 8(14):991. https://doi.org/10.1038/ ncomms 14991

Mallet PE, Claud C, Cassou C, Noer G, Kodera K (2013) Polar lows over the Nordic and Labrador Seas: synoptic circulation patterns and associations with North Atlantic-Europe wintertime weather regimes. J Geophys Res Atmos 118(6):2455-2472. https://doi. org/10.1002/jgrd.50246

Mallet PE, Claud C, Vicomte M (2017) North Atlantic polar lows and weather regimes: do current links persist in a warmer climate? Atmos Sci Lett 18(8):349-355. https://doi.org/10.1002/asl.763

Mansfield DA (1974) Polar lows: the development of baroclinic disturbances in cold air outbreaks. Q J R Meteorol Soc 100(426):541554. https://doi.org/10.1002/qj.49710042604

Noer G, Saetra Ø, Lien T, Gusdal Y (2011) A climatological study of polar lows in the Nordic Seas. Q J R Meteorol Soc 137(660):17621772. https://doi.org/10.1002/qj.846

Nordeng TE, Rasmussen EA (1992) A most beautiful polar low. A case study of a polar low development in the Bear Island region. Tellus A 44(2):81-99. https://doi.org/10.1034/j.1600-0870.1992.00001.x

Onarheim IH, Årthun M (2017) Toward an ice-free Barents Sea. Geophys Res Lett 44(16):8387-8395. https://doi.org/10.1002/2017G L074304

Park TW, Deng Y, Cai M, Jeong JH, Zhou R (2014) A dissection of the surface temperature biases in the Community Earth System Model. Clim Dyn 43(7):2043-2059. https://doi.org/10.1007/s0038 2-013-2029-9

Pithan F, Mauritsen T (2014) Arctic amplification dominated by temperature feedbacks in contemporary climate models. Nat Geosci 7(3):181-184. https://doi.org/10.1038/ngeo2071

Rasmussen EA (2011) Polar lows: mesoscale weather systems in the polar regions, reissue, edition edn. Cambridge University Press, Cambridge

Reed RJ (1979) Cyclogenesis in polar air streams. Mon Weather Rev 107(1):38-52. https://doi.org/10.1175/15200493(1979)107\%3C0038:CIPAS\%3E2.0.CO;2
Riahi K, Rao S, Krey V, Cho C, Chirkov V, Fischer G, Kindermann G, Nakicenovic N, Rafaj P (2011) RCP 8.5-a scenario of comparatively high greenhouse gas emissions. Clim Change 109(1):33. https://doi.org/10.1007/s10584-011-0149-y

Romero R, Emanuel K (2017) Climate change and Hurricane-like extratropical cyclones: projections for North Atlantic polar lows and medicanes based on CMIP5 models. J Clim 30(1):279-299. https://doi.org/10.1175/JCLI-D-16-0255.1

Selten FM, Branstator GW, Dijkstra HA, Kliphuis M (2004) Tropical origins for recent and future Northern Hemisphere climate change. Geophys Res Lett 31(21). https://doi.org/10.1029/2004GL020739

Serreze MC, Barrett AP, Stroeve J (2012) Recent changes in tropospheric water vapor over the Arctic as assessed from radiosondes and atmospheric reanalyses. J Geophys Res Atmos 117(D10). https://doi.org/10.1029/2011JD017421

Simmons AJ, Poli P (2015) Arctic warming in ERA-Interim and other analyses. Q J R Meteorol Soc 141(689):1147-1162. https://doi. org/10.1002/qj.2422

Sterl A, Severijns C, Dijkstra H, Hazeleger W, Jan van Oldenborgh G, van den Broeke M, Burgers G, van den Hurk B, Jan van Leeuwen $P$, van Velthoven P (2008) When can we expect extremely high surface temperatures? Geophys Res Lett 35(14). https://doi. org/10.1029/2008GL034071

Stoll P, Graversen RG, Noer G, Hodges K (2018) An objective global climatology of polar lows based on reanalysis data. Q J R Meteorol Soc. https://doi.org/10.1002/qj.3309

Swart NC, Fyfe JC, Hawkins E, Kay JE, Jahn A (2015) Influence of internal variability on Arctic sea-ice trends. Nat Clim Change. https://doi.org/10.1038/nclimate2483

Wilhelmsen K (1985) Climatological study of gale-producing polar lows near Norway. Tellus A Dyn Meteorol Oceanogr 37(5):451459. https://doi.org/10.3402/tellusa.v37i5.11688

Zahn M, von Storch H (2010) Decreased frequency of North Atlantic polar lows associated with future climate warming. Nature 467(7313):309-312. https://doi.org/10.1038/nature09388

Zappa G, Shaffrey LC, Hodges KI (2013) The ability of CMIP5 models to simulate North Atlantic extratropical cyclones*. J Clim 26(15):5379-5396. https://doi.org/10.1175/JCLI-D-12-00501.1

Publisher's Note Springer Nature remains neutral with regard to jurisdictional claims in published maps and institutional affiliations. 